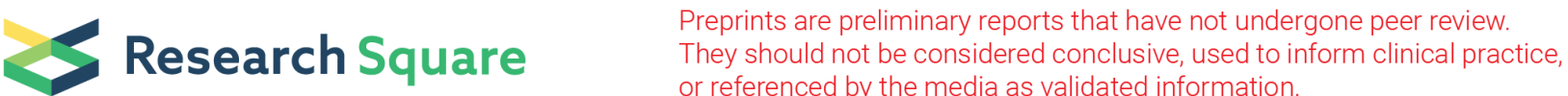

\section{The Effects of Normal Aging, Subjective Cognitive Decline, Mild Cognitive Impairment, or Alzheimer's Disease on Visual Search}

\section{Chaunwei Xue}

Capital Medical University

\section{Yi Tang}

Capital Medical University

\section{Changming Wang}

Capital Medical University

\section{Haibo Yang}

Tianjing Normal University

Liang Li ( $\sim$ liangli@pku.edu.cn )

Peking University

\section{Research article}

Keywords: Alzheimer's disease, Attention allocation, Visual search, Eye movement tracking, Cognitive load

Posted Date: November 4th, 2020

DOI: https://doi.org/10.21203/rs.3.rs-64351/v2

License: (c) (i) This work is licensed under a Creative Commons Attribution 4.0 International License. Read Full License 


\section{Abstract}

Background $\mathbb{X}$ To examine the progressively developed visual-search deficiency associated with Alzheimer's disease (AD).

Methods: Healthy-younger adults (34), healthy-older adults (normal-aging control, NC, 30), adults with subjective cognitive decline (SCD, 14), amnestic mild cognitive impairment (aMCl, 20), or mild AD (15) participated in this study. To determine whether 1 of 4 letters presented at 4 symmetrically-located positions differed from the other 3 , when the 4 letters were masked by either other randomly positioned and oriented letters or random-pixel noise. Meanwhile, eye movements were tracked.

Results: In all the participants, with the stimulus-presentation time being longer, the visual-search performance improved, and both the eye interest-area first fixation duration (IFFD) and the interest-area-fixation count (IFC) increased. Particularly under the noisemasking condition, the AD group performed the worst at stimulus-presentation times between 300 and $900 \mathrm{~ms}$. The aMCl group, but not the SCD group, performed worse than the NC group at the stimulus-presentation time of either 300 or 500 ms. The IFC was higher in all the patient groups than that in the NC group, and distinguishable between participants with AD and those with SCD or aMCl.

Conclusions: The visual-search performance combined with eye-moment tracking under the noise-masking condition can be used for distinguishing $A D$ from normal aging, $S C D$, and $\mathrm{aMCl}$.

\section{Background}

Alzheimer's disease (AD) is a disorder with both perceptual impairments and memory declines, with progressive impairments of cognitive functions, from early mild cognitive impairment to marked cognitive declines ${ }^{[1]}$. The development of $A D$ can be divided into a few stages along with disease condition, including subjective cognitive decline (SCD), amnestic mild cognitive impairment $(a M C l)$, mild $A D$, moderate $A D$, and finally, severe $A D$. The pathogenesis of $A D$ is highly correlated with aging, and also known as senile dementia ${ }^{[2]}$. The existing treatment methods cannot stop and reverse the progress of the disease ${ }^{[3,4]}$.

Up to date, the diagnostic methods roughly include three categories with various advantages and shortcomings: (1) The brainimaging method is sensitive and can accurately detect the core brain damages associated with AD. However, the disadvantage is that both the imaging equipment and the procedures are expensive, making the financial burden even worse for many families with AD patients. (2) The method of measuring cerebrospinal fluid markers is of high accuracy but the lumbar puncture is invasive. It has an adverse impact to many patients generally with low compliance from patients. (3) The method of cognitive/perceptual screening is non-invasive and less costly. There is an urgent need for further improving the cognitive/perceptual screening method to reach higher sensitivity, higher specificity, more convenience, and lower cost. AD patients with normal vision have difficulties in object recognition and spatial search ${ }^{[5-9]}$.

There is a process of integration of visual information from coarse (associated with globe attention) to fine (associated with local attention) information process in object recognition. The neural pathway underlying this function contain the principle that the lowspatial-frequency (LSF) information first comes to higher-order cortical areas, from where feedback is transmitted to lower-order cortical areas for deeper integration with high-spatial-frequency (HSF) information ${ }^{[10]}$. The process of object recognition in visual search, particularly under masking condition, is complex, including many visual and cognitive processes, involving both the dorsal visual processing pathway and the ventral visual processing pathway ${ }^{[11]}$. Thus, object recognition in visual search under masking condition ${ }^{[12]}$ should be sufficiently challenging to patients with $A D$, whose cognitive ability declines, and can be used for $A D$ screening.

Eye movement is usually involved in visual search and reflects temporal dynamics of visual processes ${ }^{[13-17]}$. Thus, this study was to establish a new visual-search paradigm combined with eye movement tracking to examine differences in visual search and eye movements between people with $\mathrm{AD}$ and people with either SCD or MCI.C

\section{Methods}

\section{Ethics Statement}


This study conformed to the Guidelines of the Declaration of Helsinki. The Ethics Committee at the Capital Medical University approved the protocol and procedures of this study. Each participant provided written informed consent prior to the start of the experiment, and received a modest stipend for their involvement.

\section{Participants}

Patient participants were recruited from the Department of Neurology and Memory Screening Clinic in the Xuan Wu Hospital in Beijing. Healthy older-adult controls with similar ages with the patients (60-70 years old) were recruited from permanent residents of Beijing in the community around the hospital, without any cognitive declines or neurological disorders, confirmed by the MMSE scale (the score was not less than 27). Younger-adult controls were all recruited from college students in Beijing, also without any cognitive declines or neurological disorders, confirmed by the MMSE scale (the score was not less than 27).

Before the study, both the participants and their family members (for patients) read the purpose of this study, precautions, and the instructions of the experiments, and all agreed to participate in the experiment with the understanding of all the rights and risks, and signed the informed consent form for participation.

The inclusion criteria were based on the neuropsychological examination reports issued by the clinicians. Based on previous studies $^{[26,27]}$, the participants with the clinical dementia rating scale (CDR) of 0 was assigned into the normal control (NC) group. After further screening with the SCDQ scale, participants meeting the conditions of subjective cognitive decline were assigned into the SCD group. Patients with the amnestic symptoms and the CDR of 0.5 were assigned into the aMCl group. Patients with the CDR of 1 were assigned into the mild AD group. If patients with the CDR larger than 2, they were in the moderate or severe $A D$ status and excluded from the participation in this study.

The age range of the younger heathy controls was between 18 and 30 years. The older healthy control group contained 30 participants and the score greater than 27 on the Mental State Examination of Mini-mental State Examination (MMSE). All the patient participants were divided into the SCD, aMCl, and mild AD groups, and their demographic data (including those of healthy participants) are shown in Table 1. All the participants had normal or corrected normal visual acuity (Tumbling E chart).

\section{Stimuli}

Each of the visual stimuli consisted of the target letters and the masking background (Figure 1). The target stimulus consisted of four symmetrically positioned English letters (font = Times New Roman, size =24 points, Figure1 top panels), which was randomly composed of either four identical or three identical letters plus one different letter (Table 2). The target-letter positions included top, bottom, left, and right positions to the center fixation point, respectively (Figure 1 top panels). Thus, the spatial pattern of the target letter position provided the low-spatial-frequency frame information determining target letters against the masking background. There were two types of masking backgrounds: (1) the letter-masking (informational masking) background containing randomly positioned and oriented letters, which were evenly distributed alone the horizontal axis and the vertical axis; (2) the random-pixel noise-masking (energetic masking) background derived from the letter masker. More in detail, through the Fourier transform of the letters, the original phase and amplitude structure of the letter masker were randomly changed to form a random pixel noise. This method preserved the root mean square (RMS) contrast of the letter masker, but eliminated the characteristics of all similar objects and produced a flat amplitude spectrum, that is, all spatial frequencies had the equal energy.

Compared with the letter masker, the noise masker retains the original RMS contrast, but destroyed any patterns similar to the characteristics of letters.

\section{Apparatus}

The participants sat in a quiet room during the experiment. The stimulus was played by a Dell computer (P1917S) with a 19-inch LCD display $(1280 \times 768$ pixels, refresh rate $=60 \mathrm{~Hz}$ ). The eye movement was tracked with an Eyelink 1000 (SR Research Company, Canada, the sampling frequency $=1000 \mathrm{~Hz}$, the resolution $\leq 0.02^{\circ}$, the accuracy $\leq 0.5^{\circ}$, and the real-time tracking delay $\leq 3 \mathrm{~ms}$ ) with a Logitech Wireless Keyboard (Logitech K375s). Using the reflection of infrared radiation on the cornea, the pupil size and the position of the point of view were measured by the camera with the sensitivity of to the infrared spectrum. The resolution of the eye position was 20 arc seconds. All the sampling and calibration were monocular (left eye). 


\section{Procedures}

The participants were given a short experimental training as formal experiment (usually continuous and complete trials for 8 times), through the simulation practice of the experiment, until the participants clearly understood the operational requirements of the experiment.

In the formal experiment, the 3 or 4 identical target letters were named "reference (ordinary)" letters, and the different (odd) one was named "different (odd) letter" (Figure 2). Upon a trial started, a "+" viewpoint was presented for 500 ms, allowing the participant to pay attention to the following stimuli. The "+" viewpoint was followed by a presentation time of target letters with 100, 300, 500, 700,900 , or $1100 \mathrm{~ms}$. After the stimulus presentation, a masking scatter with Gaussian distribution was presented immediately for $100 \mathrm{~ms}$, and the visual afterimage was eliminated. Finally, a blank screen with a duration of $3000 \mathrm{~ms}$ was presented. During the letter presentation, the participant watched the target letters against the masking background and made a judgment: pressing the keypad " 1 " when all the 4 target letters were the same, and pressing the keypad " 2 " when the 4 target letters were not the same (the reference letters were different from the odd one). In total 24 trials for each participant.

\section{Data Analyses}

Data View software was used to review data and draw the area of interest. Statistical analyses were performed using SPSS 20. GraphPad Prism 7 was used to map the results after data analyses. Two-way ANOVAs and post hoc tests were performed. Simple effects analyses were required if interactions were significant. The data were processed with GraphPad Prism 7.0 to plot the resulting images.

For statistical analyses, data were divided into behavioral data and eye-movement data. According to the categories of participants, participants were divided into the healthy control group and the patient groups, and the control group was further divided into the younger-adult group and the older-adult group. There were three patient groups including the SCD, AMCI and AD groups. The stimulus presentation time variable contained 6 levels, including 100, 300, 500, 700, 900, and 1100 ms. The masker variable contained two levels, including the letter informational masker and the noise energetic masker.

For the two healthy groups under each masker type, a 2 (age group: younger, older) × 6 (stimulus presentation time: 100, 300, 500, $700,900,1100 \mathrm{~ms}$ ) ANOVA was first conducted and then post hoc analyses were carried out to make comparisons between groups at each of the stimulus presentation times. For the four older-adult groups under each masker type, a 4 (group: NC, SCD, MCl, AD) $\times$ 6 (stimulus presentation time: 100, 300, 500, 700, 900, and $1100 \mathrm{~ms}$ ) ANOVA was first conducted and then post hoc analyses were carried out to make comparisons between groups at each of the stimulus presentation times."

\section{Results}

\section{The Effects of Normal Aging}

Figure 3 shows the results of the visual-search behavioral performance (panels a,b) and the eye tracking (panels c,d,e,f) in the healthy-younger and the healthy-older groups under either the letter masking (LM) condition (left panels) or the random noise (RN) masking condition (right panels). The visual-search performance was poor in the two groups under the LM condition, indicating that the LM condition had a much stronger masking effect than the RN-masking condition.

\section{Visual-search performance}

Under the LM condition (Figure 3a), with the increase of the stimulus presentation time, the performance in the younger group but not in the older group improved. A 2 (age group: younger, older) $\times 6$ (stimulus presentation time: 100, 300, 500, 700, 900, 1100 ms) ANOVA showed that the interaction between the stimulus presentation time and group was significant $[F(5,168)=21.83, p<0.001$, $\left.\eta p^{2}=0.59\right]$. Post hoc analyses showed that the differences in visual-search performance between the younger group and the older group under the LM condition was significant (the performance of the younger group was significantly better than that of the older group) only when the stimulus presentation time was either $700 \mathrm{~ms}$ (adjusted $p=0.002$ ) or $1100 \mathrm{~ms}$ (adjusted $p=0.0394$ ). 
Figure $3 \mathrm{~b}$ shows the visual search behavioral performance in the heathy-younger group and the healthy-older group under the RNmasking condition. With the increase of the stimulus presentation time, the performance in both groups gradually improved, and the difference between the two groups was marked. A $2 \times 6$ ANOVA showed that the interaction of stimulus presentation time and the group was significant $\left[\mathrm{F}(5,168)=37.47, p<0.001, \eta p^{2}=0.46\right]$. Post hoc analyses showed that under the RN-masking condition, at each of the stimulus presentation times, the behavioral performance of the younger group was significantly better than that of the older group (for each of the 6 presentation times, adjusted $p<0.01$ ).

\section{Eye movements}

Figure 3c shows the interest-area first fixation duration (IFFD) in the younger group and that in the older group under the LM condition. A $2 \times 6$ ANOVA showed that the interaction between group and stimulus presentation time was significant $[F(5,168)=$ 38.07, $p<0.001, \eta p^{2}=0.78$ ]. Post hoc analyses showed that the IFFD difference between the younger group and the older group under the LM condition was significant when the stimulus-presentation time was $300 \mathrm{~ms}$ (adjusted $p<0.001$ ), 700 (adjusted $p=$ 0.005), 900 (adjusted $p<0.001$ ), or $1100 \mathrm{~ms}$ (adjusted $p<0.001$ ).

Figure $3 \mathrm{~d}$ shows the IFFD in the younger healthy group and that in the older healthy group under the RN-masking condition. A $2 \times 6$ ANOVA showed that the interaction between age difference and stimulus presentation time was significant $[\mathrm{F}(5,168)=30.64(p<$ 0.001), $\eta p^{2}=0.38$ ]. Post-tests showed that the IFFD difference between the younger group and the older group under the RNmasking condition was significant when the stimulus-presentation time was 300 (adjusted $p=0.015$ ), 700 (adjusted $p<0.001$ ), or $900 \mathrm{~ms}$ (adjusted $p<0.001 ; 1100 \mathrm{~ms}$, adjusted $p<0.001$ ).

Figure 3e shows the maximum number of interest-area fixation counts (IFC) in the younger-healthy group and that in the olderhealthy group under the LM condition. A $2 \times 6$ ANOVA showed that the interaction between age group and stimulus presentation time was significant $\left[F(5,168)=8.411, p<0.001, \eta p^{2}=0.72\right]$. Post-tests showed that at the longer times $(300,500,700,900$ and $1100 \mathrm{~ms}$ ), the IFC difference between the younger group and the older group under the LM condition was significant (for all the 5 stimulus presentation times adjusted $p<0.001$ ).

Figure $3 f$ shows the maximum number of IFC of the younger healthy group and that of the older healthy group under the RNmasking condition. A $2 \times 6$ ANOVA showed that the interaction between age group and stimulus presentation time was significant $\left[F(5,168)=5.637, p<0.001, \eta p^{2}=0.42\right]$. Post hoc analyses showed that at the longer stimulus presentation times $(300,500,700$, 900 , and $1100 \mathrm{~ms}$ ), the IFC difference between the younger group and the older group under the RN-masking condition was significant (for all the five stimulus presentation times, adjusted $p<0.001$ ).

\section{The Normal Relationship between the Visual-Search Performance and the Eye Movement}

To demonstrate the normal relationship between the visual-search performance and the eye movement, Figure 4 shows the visualsearch behavioral performance as a function of the average number of IFC across individual participants in the younger healthy group under either the LM condition (left panel) or the RN-masking condition (right panel) at the 6 different stimulus presentation times. As mentioned above, both the visual-search performance improved and the IFC increased as the stimulus-presentation time became longer. There is a positive linear correlation between the behavioral performance and the IFC at either masking condition. The mathematical formula of behavioral performance (the ordinate) as a function of IFC (the abscissa) was also established (Figure 4). The slop of the regression curve for the RN-masking condition (Figure 4 right panel) is much larger than that for the LM condition (Figure 4 left panel).

\section{Comparisons between the Older-Healthy Group and Patient Groups}

Figure 5 shows the visual-search behavioral performance and the eye-tracking results in the healthy-older (normal-control, NC) group and the 3 older-patient groups (SCD, MCl, and AD) under either the LM condition (left panels) or the RN-masking condition (right panels). The visual-search performance was also very poor in each group under the LM condition than the that under the RNmasking condition (Figure 5a,b).

\section{Visual-search behavioral performance under the LM condition}

Page 5/20 
For the visual-search performance under the LM condition (Figure 5a), a 6 (stimulus presentation time: 100, 300, 500, 700, 900, and $1100 \mathrm{~ms}$ ) $\times 4$ (group: NC, SCD, MCl, AD) ANOVA showed a significant interaction between stimulus presentation time and group [F $\left.(15,336)=9.165 p<0.001, \eta p^{2}=0.30\right]$. Post hoc tests showed that there was no significant difference in behavioral performance between the NC group and the SCD group, the aMCl group or the AD group at each of the stimulus presentation times (for all the 6 stimulus presentation times, adjusted $p>0.999$ ). There was no significant difference in behavioral performance between the SCD group and the $\mathrm{aMCl}$ group or the $\mathrm{AD}$ group at each of the stimulus presentation times (for all the 6 stimulus presentation times, adjusted $p>0.999$ ). There was no significant difference in behavioral performance between the aMCl group and the AD group at each of the stimulus presentation times (for all the 6 stimulus presentation times, adjusted $p>0.999$ ).

\section{Visual-search behavioral performance under the RN-masking condition}

For the visual-search performance under the RN-masking condition (Figure 5b), a $6 \times 4$ ANOVA showed a significant interaction between stimulus presentation time and group $\left[\mathrm{F}(15,336)=17.94, p<0.001, \eta p^{2}=0.32\right]$. Post hoc tests showed that there was no significant difference in behavioral performance between the NC group and the SCD group at each of the stimulus presentation times (for all the 6 stimulus presentation times, adjusted $p>0.999$ ).

The behavioral performance of the NC group was significantly better than that of the $\mathrm{aMCl}$ when the stimulus presentation time was either $300 \mathrm{~ms}$ (adjusted $p=0.001$ ) or $500 \mathrm{~ms}$ (adjusted $p=0.02$ ).

The behavioral performance of the NC group was significantly better than that of the AD group when stimulus presentation time was $300 \mathrm{~ms}$ (adjusted $p=0.01$ ), $500 \mathrm{~ms}$ (adjusted $p=0.005$ ), $700 \mathrm{~ms}$ (adjusted $p=0.013$ ), or $900 \mathrm{~ms}$ (adjusted $p<0.001$ ).

The behavioral performance of SCD was significantly better than that of the aMCI group only when the stimulus presentation time was $300 \mathrm{~ms}$ (adjusted $p=0.003$ ).

The visual-search performance of the SCD group was significantly better than that of the AD group when the stimulus presentation time was $300 \mathrm{~ms}$ (adjusted $p=0.019), 700 \mathrm{~ms}$ (adjusted $p=0.047)$, or $900 \mathrm{~ms}$ (adjusted $p<0.001$ ).

There was no significant difference in behavioral performance between the $\mathrm{aMCl}$ and $\mathrm{AD}$ groups at each of the stimulus presentation times (for all adjusted $p>0.060$ ).

\section{Eye movement IFFD under the LM condition}

Figure $5 c$ shows the IFFD in these groups with older participants under the LM condition. With the increase of the stimulus presentation time, the IFFD in each of groups increased. A $6 \times 4$ ANOVA showed that there was a significant interaction between stimulus presentation time and group $\left[\mathrm{F}(15,336)=3.221, p<0.001, \eta p^{2}=0.49\right]$. Post hoc tests showed that under the LM condition, the IFFD of the SCD group was significantly longer than that of NC group when stimulus presentation time was $500 \mathrm{~ms}$ or larger (for the four stimulus presentation times, adjusted $p<0.001$ )..

The IFFD of the aMCl group was significantly longer than that of $\mathrm{NC}$ group when the presentation time was either 500 ms (adjusted $\mathrm{p}=0.006), 900$ (adjusted $p<0.001$ ) or $1100 \mathrm{~ms}$ (adjusted $p<0.001)$.

The IFFD of the AD group was significantly longer than that of the NC group only when the stimulus presentation time was 1100 ms (adjusted $p<0.001$ ).

The IFFD of the SCD group was significantly longer than that of the aMCl group only when the stimulus presentation time was $1100 \mathrm{~ms}$ (adjusted $p=0.002)$.

The IFFD of the SCD group was significantly longer than that of the AD group when stimulus presentation time was also $1100 \mathrm{~ms}$ (adjusted $p=0.034$ ).

There was no significant difference in IFFD between the $\mathrm{aMCl}$ group and the $\mathrm{AD}$ group at each of the 6 stimulus presentation times (for all the 6 stimulus presentation times, adjusted $p>0.999$ ). 
Figure $5 \mathrm{~d}$ shows the IFFD in the groups with older participants under the RN-masking condition. The IFFD became longer with the increase of the stimulus presentation time similarly for all the groups with older participants. A $6 \times 4$ ANOVA showed that under the $\mathrm{RN}$-masking condition there was a significant interaction between stimulus presentation time and group $[\mathrm{F}(15,336)=29.92, p<$ $0.001, \eta p^{2}=0.32$ ]. Multiple comparisons showed that when stimulus presentation time was $500 \mathrm{~ms}$ or above, the IFFD of the SCD group was significantly longer than that of the NC group (for the 4 stimulus presentation times, adjusted $p 4<0.001$ ).

The IFFD of the aMCl group was significantly longer than that of the $\mathrm{NC}$ group when the stimulus presentation time was $500 \mathrm{~ms}$ and longer (for the 4 stimulus presentation times, adjusted $p<0.001$ ).

The IFFD of the AD group was significantly longer than that of the NC group when stimulus presentation time was also $500 \mathrm{~ms}$ or longer (for the 4 stimulus presentation times, adjusted $p<0.001$ ).

The IFFD of the aMCl group was significantly longer than that of SCD group only when stimulus time was $1100 \mathrm{~ms}$ (adjusted $p=$ 0.024)..

The IFFD of the AD group was significantly longer than that of the SCD group only when the stimulus presentation time was either $900 \mathrm{~ms}$ or $1100 \mathrm{~ms}$ (for the 2 stimulus presentation times, adjusted $p<0.001$ ).

There was no significant difference in IFFD between the $\mathrm{aMCl}$ and $\mathrm{AD}$ groups at each of the stimulus presentation times (all adjusted $p>0.999$ ).

\section{The Eye movement IFC under the LM condition}

Figure $5 e$ shows the IFC in the groups with older participants under the LM condition. A $6 \times 4$ ANOVA showed that there was a significant interaction between stimulus presentation time and group $\left.[\mathrm{F}(15,336)=26.54, p<0.001), \eta p^{2}=0.22\right]$. Post hoc tests showed that between the NC and SCD there were significant differences when stimulus presentation time was 100, 300, 500, 900, or $1100 \mathrm{~ms}$ (for all adjusted $p<0.001$ ).

The IFC of the aMCl group was significantly different from that of the NC group when the stimulus presentation time was $500 \mathrm{~ms}$ or longer (for each of the 4 stimulus presentation times, adjusted $p<0.001$ ).

The IFC of the AD group was significantly higher than that of the NC group when the stimulus presentation time was either 300 ms or $900 \mathrm{~ms}$ (for the 2 stimulus presentation times, adjusted $p<0.001$ ).

The IFC of the SCD group was significantly higher than that of the aMCl group when the stimulus presentation time was 500,700 , or $1100 \mathrm{~ms}$ (for the 3 stimulus presentation times, adjusted $p<0.001$ ).

The IFC of the SCD group was significantly different from that of the AD group when the stimulus presentation time was 100,500 , 900 , or $1100 \mathrm{~ms}$ (for the 4 stimulus presentation times, adjusted $p<0.001$ ).

The IFC of the AD group was significantly higher than that of the aMCl group when the stimulus presentation time was 500 ms and above (for the 4 stimulus presentation times, adjusted $p<0.001$ )..

\section{The IFC under the RN-masking condition}

Figure 5 -f shows the maximum number of IFC across groups with older participants (groups at different developmental stages of Alzheimer's disease) under the condition of RN masking. A $6 \times 4$ ANOVA showed that there was a significant interaction between stimulus presentation time and group $\left[\mathrm{F}(15,336)=28.09, p<0.001, \eta p^{2}=0.91\right]$. Post hoc tests showed that there was a significant difference between NC and SCD only at the stimulus presentation time of 100 ms (adjusted $p<0.001$ ).

The IFC of the aMCl group was significantly higher than that of the NC group only when the stimulus presentation time was 500 $\mathrm{ms}$ (for this stimulus presentation time, adjusted $p<0.001$ ).. 
The IFC of the AD group was significantly higher than that of the NC group when the stimulus presentation time was 500,700 , or $900 \mathrm{~ms}$ (for the 3 stimulus presentation times, adjusted $p<0.001$ )..

The aMCl group was significantly different that of the SCD group when the stimulus presentation times was $100 \mathrm{~ms}$ or $500 \mathrm{~ms}$ (adjusted $p<0.001)]$.

The IFC of the AD group was significantly higher than that of the SCD group when the stimulus presentation time was 100,700 , or $900 \mathrm{~ms}$ (for the 3 stimulus presentation times, adjusted $p<0.001$ )..

The IFC of the AD group was significantly higher than that of the aMCl group when the stimulus presentation time was 500,700 , or $900 \mathrm{~ms}$ (for the 3 stimulus presentation times, adjusted $p<0.001$ ).

\section{Discussion}

For the visual research performance in this study, the spatial pattern of the positions of the 4 target letters provided low-spatialfrequency priming information for facilitating the recognition of the target letters with high-spatial information. Thus, the feedback propagation mechanism driven by the low spatial frequency information was important for the visual search performance based on a coarse-to-fine integration of information. Studies using different stimuli have confirmed the existence of such a process: low spatial frequency information is first processed and quickly projected from the primary visual cortical area to the higher-order cortical areas, and feedback information is then generated in the higher-order region to top-down modulate the processing of the high spatial frequency information in the lower-level regions ${ }^{[18-23]}$. This strategy is useful for solving the crowding problems for visual search.

The Barnikol et al. ${ }^{[24]}$ study has shown that using magnetoencephalography (MEG) with high temporal resolution, the activation of the left orbitofrontal cortex caused by object recognition is $50 \mathrm{~ms}$ earlier than that activation in the related visual sensory areas. And this earlier activation in the left orbital frontal cortex is directly affected by the low frequency information of visual stimuli, supporting the view that low-frequency information is first processed in the orbitofrontal cortex to form a prediction of the input images and then transmitted back to the ventral pathway of the temporal lobe. The visual-search paradigm used in this study specifically examine the integration of visual information from coarse (associated with the target-letter position globe attention) to fine (associated with the target-letter-feature local attention) information process in letter recognition.

As mentioned in the Introduction, $A D$ is related with progressive impairments of cognitive functions, and the development of $A D$ may pass a few stages along with aging, including $S C D$, $a M C l$, mild $A D$, moderate $A D$, and finally, severe $A D$. This study was to establish a cognitive paradigm that is useful for screening people with $A D$ in an efficient and quick way.

In this study, there were two types of maskers: the informational letter masker containing randomly positioned and oriented different letters and the energetic random-pixel noise masker. The letter masker had strong masking impact and caused floor effects.

\section{The Effects of Normal Aging}

The results of this study showed that the visual-search behavioral performance in younger-healthy group and older-healthy group under the noise masking condition could be better distinguished than that under the LM condition, because the masking effect of the LM was too strong. Specifically, under the RN-masking condition, the performance of the healthy-older group was significantly poorer than that of the healthy-younger group at each of the 6 stimulus presentation times. However, under the LM condition, the visual-search performance of the healthy-older group was significantly poorer than that of the healthy-younger group only when the stimulus presentation time was either $700 \mathrm{~ms}$ or $1000 \mathrm{~ms}$. Thus, LM condition had much stronger masking effects than the RNmasking condition. The Yang et al. study ${ }^{[25]}$ has confirmed that compared to the RN-masking condition, the LM condition has a greater interference effect on visual search and causes greater processing load in the primary visual cortex and the secondary visual cortex.

Moreover, the eye movements were also markedly different between the healthy-younger group and the healthy-older group under either the LM or the RN-masking condition. Specifically, either the IFC or the IFFD under either the LM condition or the RN masking 
condition was significantly different between the 2 healthy groups when the stimulus presentation time was 300 ms or longer.

Particularly, the IFC under the RN masking condition in the healthy-older group was markedly higher than that of the healthyyounger group when the stimulus presentation time was no less than $300 \mathrm{~ms}$. Also, in the healthy-younger group the IFC under the $\mathrm{RN}$-masking condition was correlated with the visual search performance, showing the normally functional association between the visual-search performance and the eye movement.

\section{Visual-Search Performance and Eye Movement}

The results of this study showed that under the RN-masking condition, but not the LM condition, patients with SCD were not significantly different in the visual-search performance from the healthy-older participants. However, patients with aMCl performed in the visual search significantly worse at stimulus presentation times of either 300 or $500 \mathrm{~ms}$, at which the visual-search performance in patients with aMCI was also significantly poorer than that in patients with SCD.

The stimulus presentation times, at which patients with $A D$ were significantly worse in the visual-search performance than the healthy-older participants (NC) under the RN-masking condition, included 300, 500, 700, and 900 ms. The visual-search performance in patients with AD was worse than that in patients with SCD at the stimulus presentation times of 300,700 , and 900 ms. Moreover, there was no significant difference in the behavioral performance between $\mathrm{aMCl}$ and $A D$ at each of the 6 stimulus presentation times. Thus, along the order of $\mathrm{NC}, \mathrm{SCD}, \mathrm{aMCl}$, and $\mathrm{AD}$, the visual-search performance successively got worse.

The stimulus presentation times, at which patients with AD were markedly different from the healthy-older participants (NC) in eye movement IFC under the LM condition only included $900 \mathrm{~ms}$. The stimulus presentation times, at which patients with AD were markedly different from the NC participants in IFC under the RN-masking condition included $300 \mathrm{~ms}$ and $900 \mathrm{~ms}$.

At the stimulus presentation time of $900 \mathrm{~ms}$, patients with AD were also markedly different from both patients with SCD and patients with $\mathrm{aMCl}$ in IFC under either the LM condition or the RN-masking condition.

\section{Conclusions}

By combining the visual search task and eye-movement measurement, this study established a new paradigm for screening people with $A D$. Particularly under the RN-masking condition, when the stimulus presentation time is set at 900 ms, people with $A D$ are markedly different from healthy older people in both the visual-search performance and eye-movement IFC. At these stimulus conditions, people with $A D$ are also different from people with $S C D$ and people with aMCI to certain degree in both the visualsearch performance and eye-movement IFC.

\section{Abbreviations}

$A D$, Alzheimer's disease

SCD, subjective cognitive decline

aMCl, amnestic mild cognitive impairment

LSF, low-spatial-frequency

HSF, high-spatial-frequency

$\mathrm{CDR}$, clinical dementia rating scale

NC, normal control

MMSE, Mini-mental State Examination

RMS, root mean square

Page $9 / 20$ 
LM, letter masking

$\mathrm{RN}$, random noise

IFFD, interest-area first fixation duration

IFC, interest-area fixation counts

\section{Declarations}

\section{Ethics approval and consent to participate}

This study conformed to the Guidelines of the Declaration of Helsinki. The Ethics committee at the Capital Medical University approved the protocol and procedures of this study. Each participant provided written informed consent prior to the start of the experiment, and received a modest stipend for their involvement.

\section{Consent for publication}

Not applicable.

The five authors include Chuanwei Xue, Yi Tang, Changming Wang, Haibo Yang, and Liang Li. All these authors approved the manuscript and its submission to $B M C$ Psychiatry.

\section{Availability of data and material}

Data and materials of this study are available upon requests.

\section{Competing interests}

The authors declare that they have no competing interests.

\section{Funding}

This study was supported by a grant from the '973' National Basic Research Program of China (2015CB351800) (for the design of the study, the collection, analysis, and interpretation of data, and writing the manuscript), the National Natural Science Foundation of China (31771252, 81970996)(for the design of the study, the collection, analysis, and interpretation of data, and writing the manuscript), and the Tianjin Philosophy and Social Science Project (TJJX15-002)(for the design of the study, the collection, analysis, and interpretation of data, and writing the manuscript).

\section{Authors' contributions}

CWX conducted the experiments and wrote and first manuscript draft; YT designed the study and wrote the manuscript; CMW designed the study and wrote the manuscript; HBY designed the study and wrote the manuscript; LL designed the study and wrote the manuscript. All authors have read and approved the manuscript.

\section{Acknowledgements}

The authors would like to thank all the participants and patient participants' family members.

\section{References}

1. Polikar R, Topalis A, Green D, et al. 2007. Comparative multiresolution wavelet analysis of ERP spectral bands using an ensemble of classifiers approach for early diagnosis of Alzheimer's disease. Computers in Biology \& Medicine, 37(4):542-558.

2. Small G W, Rabins P V, Barry P, et al. 1997. Diagnosis and treatment of Alzheimer disease and related disorders. Consensus statement of the American Association for Geriatric Psychiatry, the Alzheimer's Association, and the American Geriatrics Society. Jama, 278(16):1363. 
3. Nichols E, Szoeke CEl, Vollset SE, et al. 2019. Global, regional, and national burden of Alzheimer's disease and other dementias, 1990-2016: a systematic analysis for the Global Burden of Disease Study 2016. Lancet Neurology, 18(1):88-106.

4. Jianping Jia, Cuibai Wei, Shouqi Chen, Yi Tang et al. 2017. The cost of Alzheimer's disease in China and re-estimation of costs worldwide. Alzheimer's \& Dementia, 1-9.

5. Garrett K D, Browndyke J N, Whelihan W, et al. 2004. The neuropsychological profile of vascular cognitive impairment-no dementia: comparisons to patients at risk for cerebrovascular disease and vascular dementia. Arch Clin Neuropsychol, 19(6):745-757.

6. Alexander Rösler, Mapstone M, Hays-Wicklund A, et al. 2005. The "Zoom Lens" of Focal Attention in Visual Search: Changes in Aging and Alzheimer's Disease. Cortex, 41(4):512-519.

7. Fernandez-Duque D, Black S E. 2006. Attentional networks in normal aging and Alzheimer's disease. Neuropsychology, 20(2):133-143.

8. Ross L A, Clay O J, Edwards J D, et al. 2009. Do Older Drivers At-Risk for Crashes Modify Their Driving Over Time? Journals of Gerontology, 64(2):163-170.

9. Uc E Y, Rizzo M, Anderson S W, et al. 2004. Driver route-following and safety errors in early Alzheimer disease. Neurology, 63(5):832-7.

10. Halit H, Haan M D, Schyns P G, et al. 2006. Is high-spatial frequency information used in the early stages of face detection? Brain Research, 1117(1):154-161.

11. Franz E A, Eliassen J C, Ivry R B, et al. 2010. Dissociation of spatial and temporal coupling in the bimanual movements of callosotomy patients. Psychological Science, 7(5):306-310.

12. Gao Y Y, Schneider B, Li L. 2016. The effects of the binocular disparity differences between targets and maskers on visual search. attention perception \& psychophysics, 79(2):1-14.

13. Parasuraman, R., Greenwood, P. M., Haxby, J. V., \& Grady, C. L. (1992). Visuospatial attention in dementia of the Alzheimer type. Brain, 115, 711-733).

14. Parasuraman, R., Greenwood, P. M., \& Alexander, G. E. (1995). Selective impairment of spatial attention during visual search in Alzheimer's disease. Neuroreport, 6,1861-1864.

15. Parasuraman R, Greenwood P M, Alexander G E. 2000. Alzheimer disease constricts the dynamic range of spatial attention in visual search. Neuropsychologia, 38(8):1126-1135.

16. RÖSler A, Billino J, MÜLler N G, et al. 2005. Visual Search in Patients with Subcortical Vascular Dementia: Short Fixations but Long Reaction Times. Dementia and Geriatric Cognitive Disorders, 20(6):375-380.

17. Cosman, J. D., Lees, M. N., Lee, J. D., Matthew, R. \& Vecera, S. P. 2011. Impaired attentional disengagement in older adults with useful field of view decline. Journals of Gerontology Series B: Psychological Sciences, (4), 4.

18. Parker D M, Dutch S. 1987. Perceptual latency and spatial frequency. Vision Research, 27(8):1279-1283.

19. Parker D M, Lishman J R, Hughes J. 1992. Temporal integration of spatially filtered visual images. Perception, 21(2):147-160.

20. Goffaux V, Peters J, Haubrechts J, et al. 2011. From Coarse to Fine? Spatial and Temporal Dynamics of Cortical Face Processing. Cerebral Cortex, 21(2):467-476.

21. Macphail E M, Good M, Honey R C, et al. 1995. Relational learning in pigeons: The role of perceptual processes in between-key recognition of complex stimuli. Learning \& Behavior, 23(1):83-92.

22. Lu Y, Yin J, Chen Z, et al. 2018. Revealing Detail along the Visual Hierarchy: Neural Clustering Preserves Acuity from V1 to V4. Neuron, 98(2): S0896627318301867.

23. Finlayson N J, Zhang X, Golomb J D. 2017. Differential patterns of 2D location versus depth decoding along the visual hierarchy. Neuroimage, 147(Complete):507-516.

24. Barnikol U B, Amunts K, Dammers J, et al. 2006. Pattern reversal visual evoked responses of V1/V2 and V5/MT as revealed by MEG combined with probabilistic cytoarchitectonic maps. Neuroimage, 31(1):86-108.

25. YANG Haibo, LIU Hejun, ZHANG Peng, LI Liang. 2019. The role of masking stimulation in target recognition processing: Evidence from fNIRS. Acta Psychologica Sinica, Vol. 51, No.11, 1187-1197. 
26. Krueger, C. E. , Laluz, V. , Rosen, H. J, et al. 2011. Double dissociation in the anatomy of socioemotional disinhibition and executive functioning in dementia. Neuropsychology, 25(2), 249.

27. Verloo, H., Alexandre, Salina, A., \& Fiorentino, A., Cohen, C. 2018. Factors influencing the quality of life perceptions of cognitively impaired older adults in a nursing home and their informal and professional caregivers: a mixed methods study. Clinical Interventions in Aging, 13, 2135-2147.

\section{Tables}

Table 1. Demographic Statistics

Group Age (years) Educational level (years) Gender Number

\begin{tabular}{|c|c|c|c|c|}
\hline YC\younger heathy control group $\square$ & $23.0 \pm 2.1$ & $17 \pm 1.5$ & Males & 6 \\
\hline & & & Females & 28 \\
\hline \multirow[t]{2}{*}{ NC $₫$ Normal older healthy control group $\square$} & $65.0 \pm 5.8$ & $13 \pm 3.2$ & Males & 12 \\
\hline & & & Females & 18 \\
\hline \multirow[t]{2}{*}{ SCD } & $67.6 \pm 7.716$ & $12 \pm 8.1$ & Males & 7 \\
\hline & & & Females & 7 \\
\hline \multirow[t]{2}{*}{$\mathrm{aMCI}$} & $68.9 \pm 6.30$ & $12 \pm 6.0$ & Males & 8 \\
\hline & & & Females & 12 \\
\hline \multirow[t]{2}{*}{$\mathrm{AD}$} & $70.1 \pm 7.7$ & $11 \pm 3.2$ & Males & 8 \\
\hline & & & Females & 7 \\
\hline
\end{tabular}

Table 2. The Fifteen Target Letters Used in the Experiment 


\begin{tabular}{|c|c|}
\hline Reference Letter & Different (odd) Letter \\
\hline $\mathrm{O}$ & $\mathrm{U}$ \\
\hline $\mathrm{G}$ & $\mathrm{C}$ \\
\hline B & $\mathrm{R}$ \\
\hline $\mathrm{Q}$ & $\mathrm{D}$ \\
\hline $\mathrm{T}$ & $\mathrm{F}$ \\
\hline $\mathrm{A}$ & $\mathrm{H}$ \\
\hline $\mathrm{W}$ & M \\
\hline $\mathrm{U}$ & $\mathrm{V}$ \\
\hline $\mathrm{V}$ & $\mathrm{Y}$ \\
\hline M & $\mathrm{N}$ \\
\hline $\mathrm{J}$ & $\mathrm{L}$ \\
\hline B & $\mathrm{W}$ \\
\hline $\mathrm{O}$ & $\mathrm{D}$ \\
\hline $\mathrm{X}$ & $\mathrm{K}$ \\
\hline $\mathrm{P}$ & $\mathrm{D}$ \\
\hline
\end{tabular}

Table 3. The Results of the Visual-Search Behavioral Performance and the Eye Tracking in the Younger Healthy Normal Group and the Older Healthy Normal Group 


\begin{tabular}{|c|c|c|c|c|c|c|c|c|c|c|c|c|c|}
\hline \multicolumn{2}{|c|}{ Masking } & \multicolumn{6}{|c|}{ LM } & \multicolumn{6}{|c|}{$\mathrm{RN}$} \\
\hline Time & ns) & 100 & 300 & 500 & 700 & 900 & 1100 & 100 & 300 & 500 & 700 & 900 & 1100 \\
\hline \multirow[t]{2}{*}{$\begin{array}{l}\text { Percent } \\
\text { Correct } \\
(\%)\end{array}$} & Younger & $\begin{array}{c}51.23 \\
\pm \\
1.52\end{array}$ & $\begin{array}{r}53.72 \\
\pm 1.83\end{array}$ & $\begin{array}{r}54.48 \\
\pm 1.52\end{array}$ & $\begin{array}{c}56.3 \pm \\
1.53\end{array}$ & $\begin{array}{r}56.57 \\
\pm 1.63\end{array}$ & $\begin{array}{r}57.18 \\
\pm 1.62\end{array}$ & $\begin{array}{c}92.66 \\
\pm \frac{ \pm}{1.26}\end{array}$ & $\begin{array}{r}95.45 \\
\pm 1.21\end{array}$ & $\begin{array}{r}97.64 \\
\pm 2.15\end{array}$ & $\begin{array}{r}97.97 \\
\pm 2.14\end{array}$ & $\begin{array}{c}97.97 \\
\pm 1.14\end{array}$ & $\begin{array}{r}98.03 \\
\pm 1.04\end{array}$ \\
\hline & Older & $\begin{array}{l}53.92 \\
\pm \\
2.27\end{array}$ & $\begin{array}{r}56.47 \\
\pm 1.26\end{array}$ & $\begin{array}{r}59.03 \\
\pm 2.31\end{array}$ & $\begin{array}{c}43.19 \\
\pm 1.28\end{array}$ & $\begin{array}{r}55.12 \\
\pm 2.34\end{array}$ & $\begin{array}{r}50.46 \\
\pm 1.31\end{array}$ & $\begin{array}{c}67.92 \\
\pm \\
2.15\end{array}$ & $\begin{array}{r}79.49 \\
\pm 2.26\end{array}$ & $\begin{array}{c}72.91 \\
\pm 1.45\end{array}$ & $\begin{array}{r}74.16 \\
\pm 1.71\end{array}$ & $\begin{array}{r}81.13 \\
\pm 1.35\end{array}$ & $\begin{array}{r}82.32 \\
\pm 1.26\end{array}$ \\
\hline \multirow{2}{*}{$\begin{array}{c}\text { Interest } \\
\text { Area First } \\
\text { Fixation } \\
\text { Duration } \\
\text { (ms) }\end{array}$} & Younger & $\begin{array}{c}72.06 \\
\pm \\
12.98\end{array}$ & $\begin{array}{c}150.70 \\
\pm \\
75.64\end{array}$ & $\begin{array}{c}236.40 \\
\pm \\
58.46\end{array}$ & $\begin{array}{c}269.40 \\
\pm \\
67.98\end{array}$ & $\begin{array}{c}281.70 \\
\pm \\
98.58\end{array}$ & $\begin{array}{c}292.60 \\
\pm \\
88.09\end{array}$ & $\begin{array}{c}71.76 \\
\pm \\
36.64\end{array}$ & $\begin{array}{c}161.60 \\
\pm \\
56.70\end{array}$ & $\begin{array}{c}221.50 \\
\pm \\
36.54\end{array}$ & $\begin{array}{c}254.10 \\
\pm \\
72.11\end{array}$ & $\begin{array}{c}269.30 \\
\pm \\
66.84\end{array}$ & $\begin{array}{c}274.90 \\
\pm \\
85.26\end{array}$ \\
\hline & Older & $\begin{array}{c}77.00 \\
\pm \\
19.29\end{array}$ & $\begin{array}{c}102.90 \\
\pm \\
72.06\end{array}$ & $\begin{array}{c}244.20 \\
\pm \\
77.49\end{array}$ & $\begin{array}{c}290.30 \\
\pm \\
69.77\end{array}$ & $\begin{array}{c}332.20 \\
\pm \\
87.54\end{array}$ & $\begin{array}{c}337.30 \\
\pm \\
98.06\end{array}$ & $\begin{array}{c}77.00 \\
\pm \\
22.58\end{array}$ & $\begin{array}{c}144.70 \\
\pm \\
72.66\end{array}$ & $\begin{array}{c}256.60 \\
\pm \\
83.98\end{array}$ & $\begin{array}{c}265.90 \\
\pm \\
89.52\end{array}$ & $\begin{array}{c}224.50 \\
\pm \\
78.13\end{array}$ & $\begin{array}{c}233.50 \\
\pm \\
75.48\end{array}$ \\
\hline \multirow{2}{*}{$\begin{array}{l}\text { Interest } \\
\text { Area } \\
\text { Fixation } \\
\text { Count } \\
\text { (max) }\end{array}$} & Younger & $\begin{array}{l}2.00 \\
\pm \\
1.03\end{array}$ & $\begin{array}{c}3.00 \pm \\
1.08\end{array}$ & $\begin{array}{c}4.00 \pm \\
1.17\end{array}$ & $\begin{array}{c}4.00 \pm \\
1.18\end{array}$ & $\begin{array}{c}4.00 \pm \\
1.25\end{array}$ & $\begin{array}{c}4.00 \pm \\
1.27\end{array}$ & $\begin{array}{l}2.00 \\
\pm \\
1.03\end{array}$ & $\begin{array}{c}3.00 \pm \\
1.09\end{array}$ & $\begin{array}{c}3.00 \pm \\
1.13\end{array}$ & $\begin{array}{c}4.00 \pm \\
1.15\end{array}$ & $\begin{array}{c}4.00 \pm \\
1.17\end{array}$ & $\begin{array}{c}6.00 \pm \\
1.19\end{array}$ \\
\hline & Older & $\begin{array}{l}2.00 \\
\pm \\
1.11\end{array}$ & $\begin{array}{c}2.00 \pm \\
1.05\end{array}$ & $\begin{array}{c}3.00 \pm \\
1.18\end{array}$ & $\begin{array}{c}3.00 \pm \\
1.26\end{array}$ & $\begin{array}{c}5.00 \pm \\
1.28\end{array}$ & $\begin{array}{c}6.00 \pm \\
1.36\end{array}$ & $\begin{array}{l}2.00 \\
\pm \\
1.01\end{array}$ & $\begin{array}{c}2.00 \pm \\
1.11\end{array}$ & $\begin{array}{c}2.00 \pm \\
1.07\end{array}$ & $\begin{array}{c}3.00 \pm \\
1.19\end{array}$ & $\begin{array}{c}3.00 \pm \\
1.17\end{array}$ & $\begin{array}{c}3.00 \pm \\
1.23\end{array}$ \\
\hline
\end{tabular}

Table 4. The Visual-Search and Eye-Tracking Results of the Older Healthy Normal Control (NC) Group and the Three Patient Groups $(\mathrm{SCD}, \mathrm{aMCl}, \mathrm{AD})$ 


\begin{tabular}{|c|c|c|c|c|c|c|c|c|c|c|c|c|c|}
\hline \multirow{2}{*}{\multicolumn{2}{|c|}{$\begin{array}{l}\text { Masking } \\
\text { Time\ms) }\end{array}$}} & \multicolumn{6}{|c|}{ LM } & \multicolumn{6}{|c|}{$\overline{\mathrm{RN}}$} \\
\hline & & 100 & 300 & 500 & 700 & 900 & 1100 & 100 & 300 & 500 & 700 & 900 & 1100 \\
\hline \multirow[t]{4}{*}{$\begin{array}{c}\text { Percent } \\
\text { Correct (\%) }\end{array}$} & $\mathrm{NC}$ & $\begin{array}{c}53.92 \\
\pm \\
2.27\end{array}$ & $\begin{array}{r}56.47 \\
\pm 1.26\end{array}$ & $\begin{array}{r}59.03 \\
\pm 2.31\end{array}$ & $\begin{array}{r}43.19 \\
\pm 1.28\end{array}$ & $\begin{array}{l}55.12 \\
\pm 2.34\end{array}$ & $\begin{array}{r}50.46 \\
\pm 1.31\end{array}$ & $\begin{array}{c}67.92 \\
\pm \pm \\
2.15\end{array}$ & $\begin{array}{r}79.49 \\
\pm 2.26\end{array}$ & $\begin{array}{r}72.91 \\
\pm 1.45\end{array}$ & $\begin{array}{r}74.16 \\
\pm 1.71\end{array}$ & $\begin{array}{r}81.13 \\
\pm 1.35\end{array}$ & $\begin{array}{r}82.32 \\
\pm 1.26\end{array}$ \\
\hline & SCD & $\begin{array}{c}46.43 \\
\pm \\
4.73\end{array}$ & $\begin{array}{c}49.11 \\
\frac{ \pm}{7}\end{array}$ & $\begin{array}{l}49.11 \\
\pm 5.21\end{array}$ & $\begin{array}{c}48.21 \\
\pm 3.66\end{array}$ & $\begin{array}{r}48.15 \\
\pm 1.28\end{array}$ & $\begin{array}{l}50.93 \\
\pm \frac{ \pm}{2} 5\end{array}$ & $\begin{array}{c}67.86 \\
\frac{ \pm}{ \pm} 1\end{array}$ & $\begin{array}{c}78.7 \pm \\
2.14\end{array}$ & $\begin{array}{r}66.96 \\
\pm 2.35\end{array}$ & $\begin{array}{l}72.07 \\
\pm \pm \\
2.08\end{array}$ & $\begin{array}{r}85.19 \\
\pm 3.12\end{array}$ & $\begin{array}{c}87.27 \\
\pm \\
2.05\end{array}$ \\
\hline & aMCI & $\begin{array}{c}54.27 \\
\pm \\
3.90\end{array}$ & $\begin{array}{r}50.00 \\
\pm 3.86\end{array}$ & $\begin{array}{c}48.21 \\
\pm 3.86\end{array}$ & $\begin{array}{r}50.00 \\
\pm 5.21\end{array}$ & $\begin{array}{r}54.76 \\
\pm 3.21\end{array}$ & $\begin{array}{r}50.00 \\
\pm 2.15\end{array}$ & $\begin{array}{c}67.31 \\
\frac{ \pm}{3.74}\end{array}$ & $\begin{array}{c}61.96 \\
\frac{ \pm}{3.75}\end{array}$ & $\begin{array}{c}58.79 \\
\pm \pm \\
4.02\end{array}$ & $\begin{array}{c}69.7 \pm \\
3.64\end{array}$ & $\begin{array}{r}72.89 \\
\pm 2.98\end{array}$ & $\begin{array}{c}82.32 \\
\pm \frac{ \pm}{2} 2\end{array}$ \\
\hline & $\mathrm{AD}$ & $\begin{array}{c}48.15 \\
\pm \frac{ \pm}{4.38}\end{array}$ & $\begin{array}{r}53.64 \\
\pm 3.55\end{array}$ & $\begin{array}{r}50.89 \\
\pm 4.28\end{array}$ & $\begin{array}{c}48.21 \\
\pm 3.69\end{array}$ & $\begin{array}{l}50.89 \\
\pm 2.45\end{array}$ & $\begin{array}{l}50.00 \\
\pm 2.96\end{array}$ & $\begin{array}{c}58.88 \\
\frac{ \pm}{5} \\
4.56\end{array}$ & $\begin{array}{c}64.15 \\
\frac{ \pm}{5} \\
4.54\end{array}$ & $\begin{array}{c}56.36 \\
\pm . \frac{ \pm}{32}\end{array}$ & $\begin{array}{c}58.93 \\
\pm .48\end{array}$ & $\begin{array}{c}59.82 \\
\pm \frac{ \pm}{487}\end{array}$ & 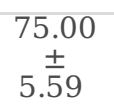 \\
\hline \multirow[t]{4}{*}{$\begin{array}{l}\text { Interest Area } \\
\text { First Fixation } \\
\text { Duration } \\
\text { (ms) }\end{array}$} & $\mathrm{NC}$ & $\begin{array}{c}77.00 \\
\pm \\
19.29\end{array}$ & $\begin{array}{c}102.90 \\
\pm \\
72.06\end{array}$ & $\begin{array}{c}244.20 \\
\pm \\
77.49\end{array}$ & $\begin{array}{c}290.30 \\
\pm \\
69.77\end{array}$ & $\begin{array}{c}332.20 \\
\pm \\
87.54\end{array}$ & $\begin{array}{c}337.30 \\
\pm \\
98.06\end{array}$ & $\begin{array}{c}77.00 \\
\pm \\
22.58\end{array}$ & $\begin{array}{c}144.70 \\
\pm \\
72.66\end{array}$ & $\begin{array}{c}256.60 \\
\pm \\
83.98\end{array}$ & $\begin{array}{c}265.90 \\
\pm \\
89.52\end{array}$ & $\begin{array}{c}224.50 \\
\pm \\
78.13\end{array}$ & $\begin{array}{c}233.50 \\
\pm \\
75.48\end{array}$ \\
\hline & SCD & $\begin{array}{c}78.67 \\
\pm \\
17.89\end{array}$ & $\begin{array}{c}175.60 \\
\pm \\
16.29\end{array}$ & $\begin{array}{c}244.50 \\
\pm \\
15.37\end{array}$ & $\begin{array}{c}284.50 \\
\pm \\
59.29\end{array}$ & $\begin{array}{c}307.70 \\
\pm \\
60.58\end{array}$ & $\begin{array}{c}326.70 \\
\pm \\
75.19\end{array}$ & $\begin{array}{c}95.00 \\
\pm \\
18.55\end{array}$ & $\begin{array}{c}161.00 \\
\pm \\
11.65\end{array}$ & $\begin{array}{c}231.40 \\
\pm \\
18.20\end{array}$ & $\begin{array}{c}215.90 \\
\pm \\
59.29\end{array}$ & $\begin{array}{c}234.30 \\
\pm \\
78.16\end{array}$ & $\begin{array}{c}250.30 \\
\pm \\
88.31\end{array}$ \\
\hline & aMCI & $\begin{array}{c}80.50 \\
\pm \\
10.25\end{array}$ & $\begin{array}{c}166.20 \\
\pm \\
28.34\end{array}$ & $\begin{array}{c}220.80 \\
\pm \\
15.64\end{array}$ & $\begin{array}{c}267.80 \\
\pm \\
25.45\end{array}$ & $\begin{array}{c}304.30 \\
\pm \\
21.96\end{array}$ & $\begin{array}{c}332.70 \\
\pm \\
38.81\end{array}$ & $\begin{array}{c}64.86 \\
\pm \\
11.23\end{array}$ & $\begin{array}{c}142.00 \\
\pm \\
46.32\end{array}$ & $\begin{array}{c}211.00 \\
\pm \\
58.46\end{array}$ & $\begin{array}{c}204.40 \\
\pm \\
56.89\end{array}$ & $\begin{array}{c}245.00 \\
\pm \\
61.23\end{array}$ & $\begin{array}{c}239.50 \\
\pm \\
67.98\end{array}$ \\
\hline & $\mathrm{AD}$ & $\begin{array}{c}72.75 \\
\pm \\
21.25\end{array}$ & $\begin{array}{c}143.90 \\
\pm \\
44.88\end{array}$ & $\begin{array}{c}274.90 \\
\pm \\
57.61\end{array}$ & $\begin{array}{c}346.10 \\
\pm \\
58.19\end{array}$ & $\begin{array}{c}334.00 \\
\pm \\
78.34\end{array}$ & $\begin{array}{c}330.90 \\
\pm \\
80.99\end{array}$ & $\begin{array}{c}66.00 \\
\pm \\
36.32\end{array}$ & $\begin{array}{c}143.30 \\
\pm \\
45.25\end{array}$ & $\begin{array}{c}227.70 \\
\pm \\
52.92\end{array}$ & $\begin{array}{c}236.90 \\
\pm \\
70.61\end{array}$ & $\begin{array}{c}264.70 \\
\pm \\
72.53\end{array}$ & $\begin{array}{c}291.80 \\
\pm \\
78.68\end{array}$ \\
\hline \multirow[t]{4}{*}{$\begin{array}{l}\text { Interest Area } \\
\text { Fixation } \\
\text { Count (max) }\end{array}$} & $\mathrm{NC}$ & $\begin{array}{l}2.00 \\
\pm \pm \\
1.11\end{array}$ & $\begin{array}{l}2.00 \pm \\
1.05\end{array}$ & $\begin{array}{l}3.00 \pm \\
1.18\end{array}$ & $\begin{array}{c}3.00 \pm \\
1.26\end{array}$ & $\begin{array}{l}5.00 \pm \\
1.28\end{array}$ & $\begin{array}{l}6.00 \pm \\
1.36\end{array}$ & $\begin{array}{l}2.00 \\
\pm \\
1.01\end{array}$ & $\begin{array}{c}2.00 \pm \\
1.11\end{array}$ & $\begin{array}{c}2.00 \pm \\
1.07\end{array}$ & $\begin{array}{l}3.00 \pm \\
1.19\end{array}$ & $\begin{array}{c}3.00 \pm \\
1.17\end{array}$ & $\begin{array}{l}3.00 \pm \\
1.23\end{array}$ \\
\hline & SCD & $\begin{array}{l}1.00 \\
\pm \\
1.68\end{array}$ & $\begin{array}{l}3.00 \pm \\
1.03\end{array}$ & $\begin{array}{c}4.00 \pm \\
1.90\end{array}$ & $\begin{array}{l}3.00 \pm \\
1.68\end{array}$ & $\begin{array}{l}3.00 \pm \\
1.10\end{array}$ & $\begin{array}{c}4.00 \pm \\
1.21\end{array}$ & $\begin{array}{l}1.00 \\
\pm \\
1.11\end{array}$ & $\begin{array}{c}2.00 \pm \\
1.00\end{array}$ & $\begin{array}{c}4.00 \pm \\
1.87\end{array}$ & $\begin{array}{l}3.00 \pm \\
1.54\end{array}$ & $\begin{array}{l}3.00 \pm \\
1.38\end{array}$ & $\begin{array}{c}3.00 \pm \\
1.17\end{array}$ \\
\hline & aMCI & $\begin{array}{l}2.00 \\
\frac{ \pm}{1.75}\end{array}$ & $\begin{array}{c}3.00 \pm \\
1.54\end{array}$ & $\begin{array}{l}2.00 \pm \\
1.05\end{array}$ & $\begin{array}{c}2.00 \pm \\
1.08\end{array}$ & $\begin{array}{l}3.00 \pm \\
1.28\end{array}$ & $\begin{array}{l}3.00 \pm \\
2.10\end{array}$ & $\begin{array}{l}2.00 \\
\pm \\
1.41\end{array}$ & $\begin{array}{c}2.00 \pm \\
1.07\end{array}$ & $\begin{array}{l}3.00 \pm \\
1.72\end{array}$ & $\begin{array}{c}3.00 \pm \\
1.54\end{array}$ & $\begin{array}{l}3.00 \pm \\
1.62\end{array}$ & $\begin{array}{l}3.00 \pm \\
1.78\end{array}$ \\
\hline & $\mathrm{AD}$ & $\begin{array}{l}2.00 \\
\pm \\
1.56\end{array}$ & $\begin{array}{l}3.00 \pm \\
1.32\end{array}$ & $\begin{array}{c}3.00 \pm \\
1.01\end{array}$ & $\begin{array}{l}3.00 \pm \\
1.42\end{array}$ & $\begin{array}{l}6.00 \pm \\
3.22\end{array}$ & $\begin{array}{l}5.00 \pm \\
3.11\end{array}$ & $\begin{array}{l}2.00 \\
\pm \\
1.12\end{array}$ & $\begin{array}{c}2.00 \pm \\
1.74\end{array}$ & $\begin{array}{l}4.00 \pm \\
1.17\end{array}$ & $\begin{array}{c}4.00 \pm \\
1.77\end{array}$ & $\begin{array}{l}5.00 \pm \\
2.95\end{array}$ & $\begin{array}{l}3.00 \pm \\
2.08\end{array}$ \\
\hline
\end{tabular}

\section{Figures}



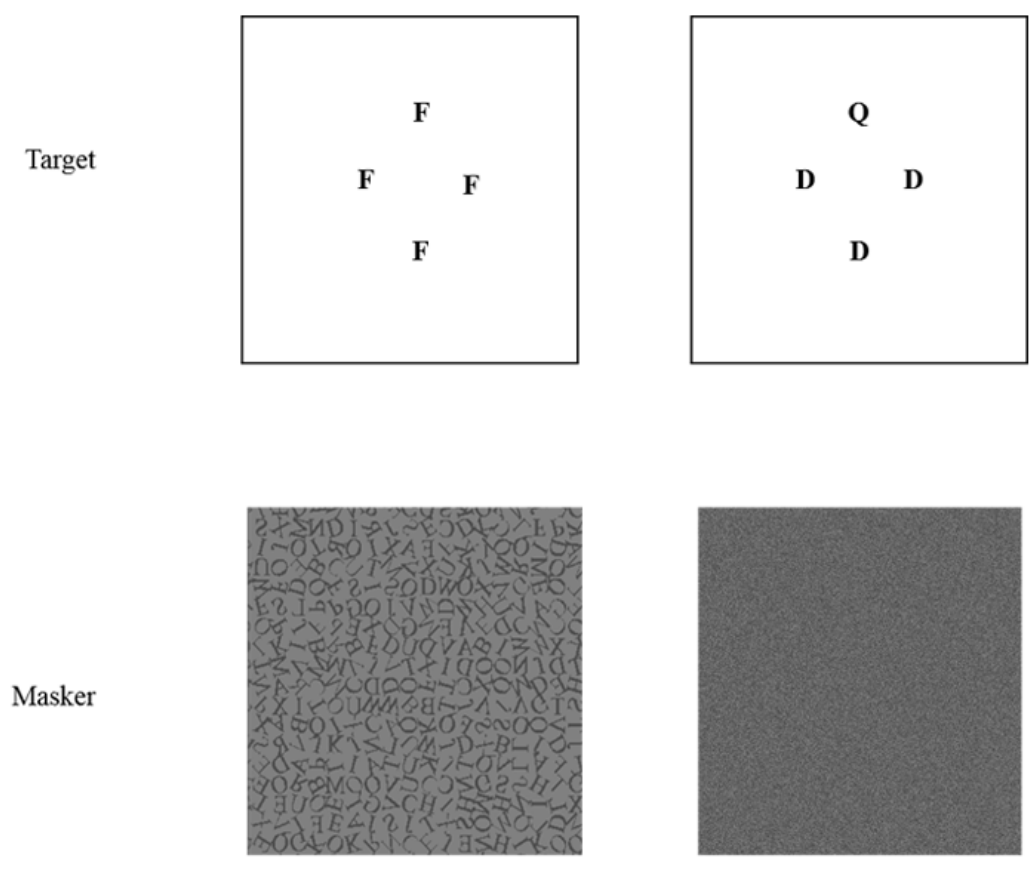

Target on Masker
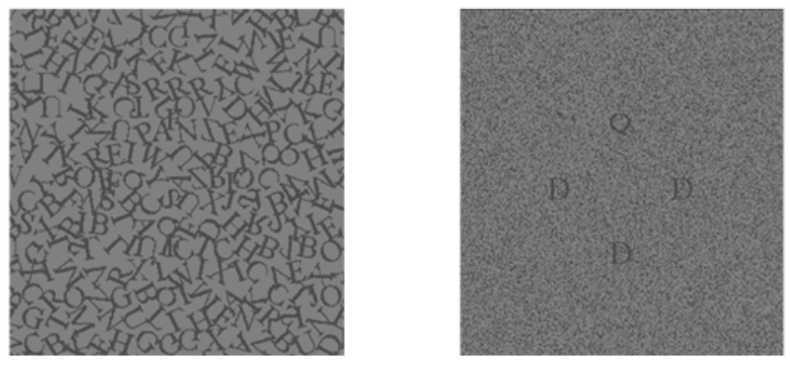

\section{Figure 1}

The four positions of the target letters and the two different types of maskers. A: Letter Masker. B: Random Pixel Masker. 


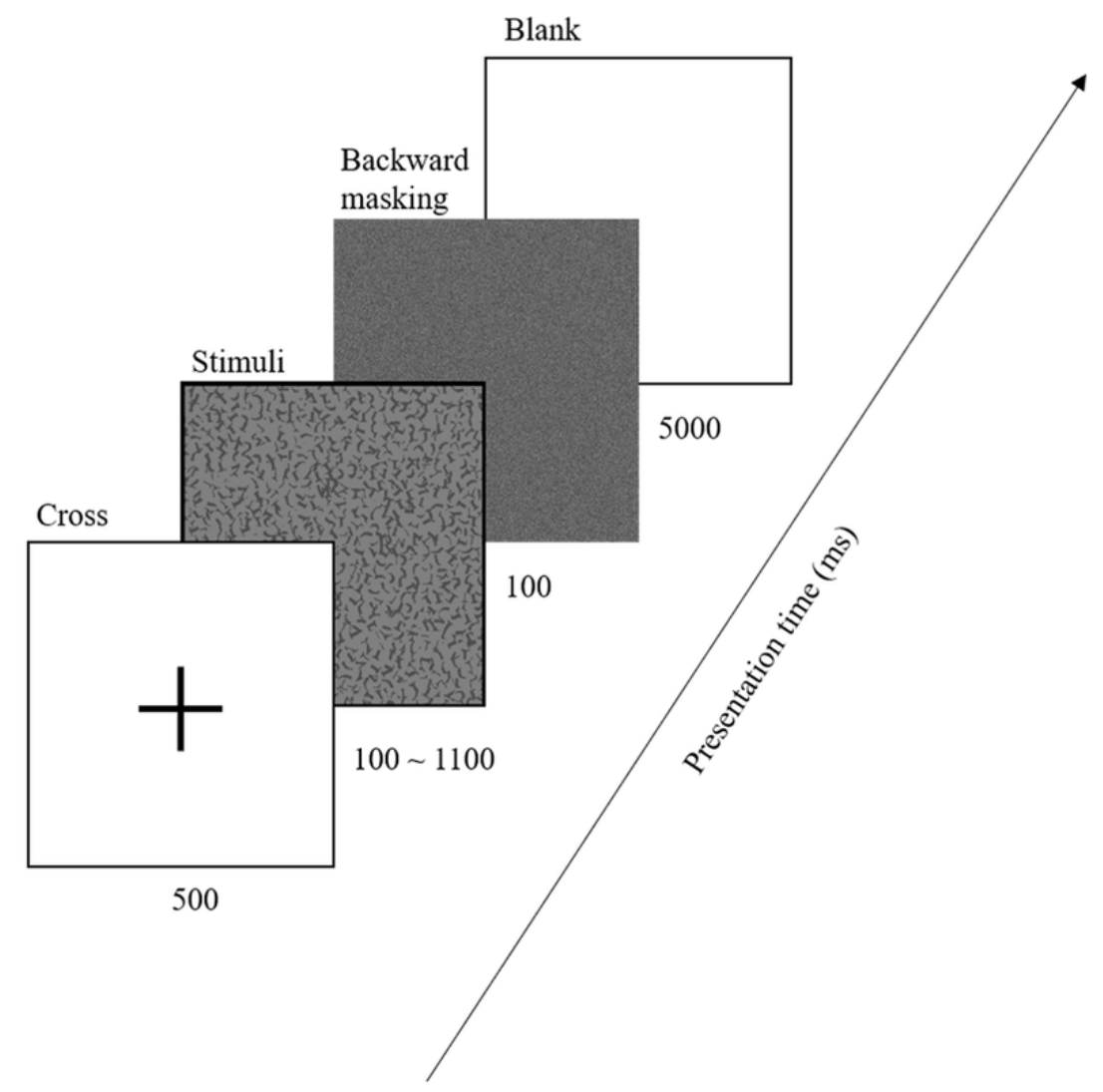

\section{Figure 2}

The sequence of events in the experiment. The direction of the arrows indicates the sequence of the events in a trial. After the 500millisecond fixation cross, the target stimulus and mask were presented with a duration of $100,300,500,700,900$, or 1100 milliseconds, followed by a 100-millisecond random point masker, and then a blank screen was presented during the response period. 

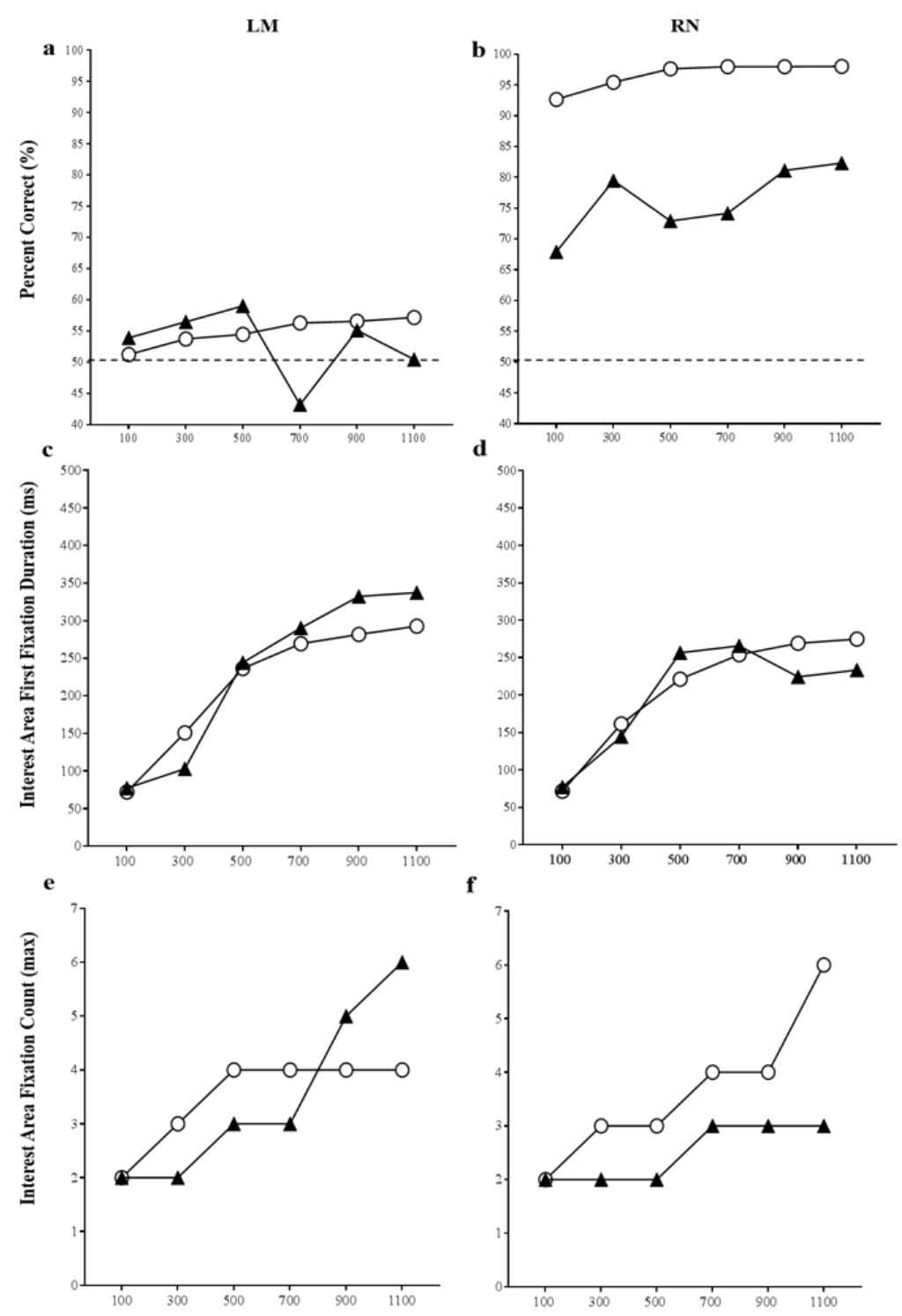

Stimulus Presentation Times (ms)

Younger

$\Delta$ Older

\section{Figure 3}

Under either the informational letter masking (LM, left panels) condition or the random-noise (RN, right panels) masking condition, the visual-search performance (Panels $a, b$ ), the interest area first fixation duration (IFFD, Panels $c, d$ ), and the maximum value of the interest area fixation count (IFC, Panels $\mathrm{e}, \mathrm{f}$ ) at each of the 6 stimulus presentation times in the healthy younger group and the healthy older group. In Panel a and Panel b, the broken line represent the 50\% correct performance. 


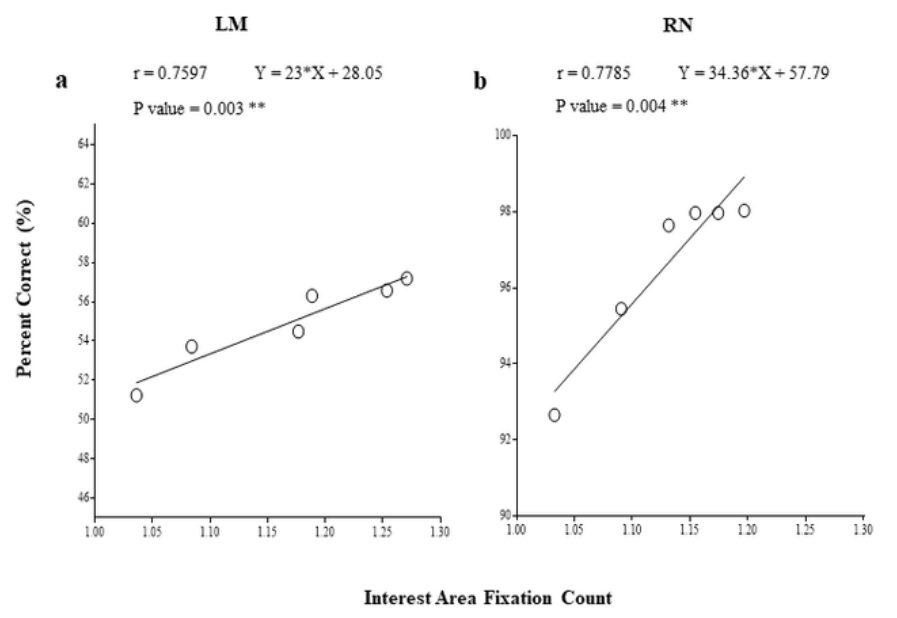

\section{Figure 4}

The correlation between the behavioral performance and the time IFC (average) associated with various stimulus presentation times in the younger healthy group under either the informational letter masking (LM, left panel) condition or the random-noise (RN, right panel) masking condition. *, $\mathrm{p}<0.05, * *, \mathrm{p}<0.01$. 

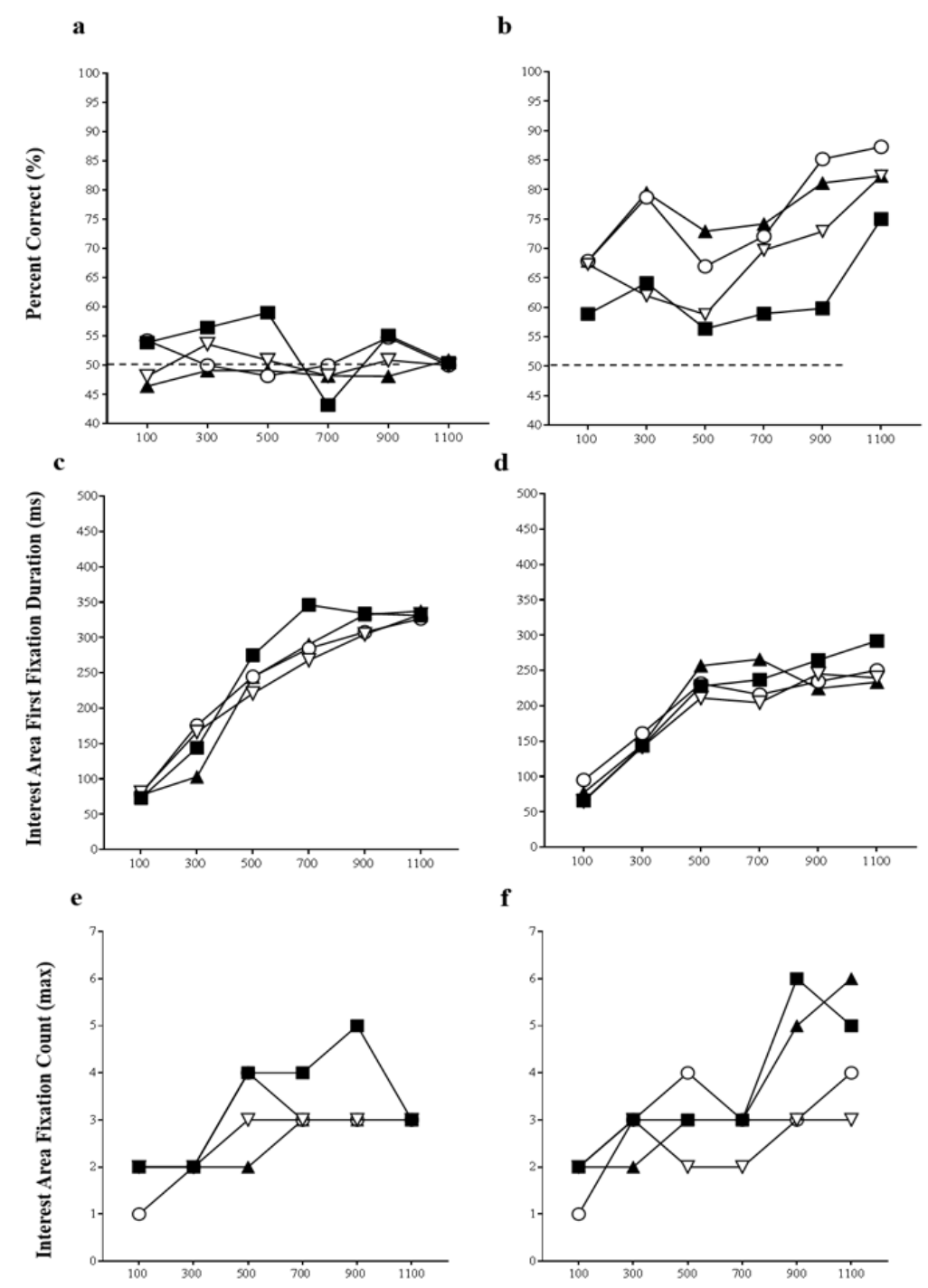

Stimulus Presentation Times (ms)

$\boldsymbol{\Delta}$ Older $\bigcirc \operatorname{scD} \nabla$ aMCI $\boldsymbol{a D}$

\section{Figure 5}

Under either the informational letter masking (LM, left panels) condition or the random-noise (RN, right panels) masking condition, the visual-search performance (Panels $a, b$ ), the interest area first fixation duration (IFFD, Panels $c, d$ ), and the maximum value of the interest area fixation count (IFC, Panels e, $\mathrm{f}$ ) at each of the 6 stimulus presentation times in the healthy older (normal control, 